\title{
Complications of Laparoscopic Versus Open Nephrectomy for Xanthogranulomatous Pyelonephritis: A Contemporary Series
}

\author{
Neel Raval, Justin Benabdallah, Leslie Selden L, Joel Vetter, Ramakrishna Ven- \\ katesh $R^{*}$ and Robert S Figenshau
}

Division of Urologic Surgery, Washington University School of Medicine in St. Louis, USA

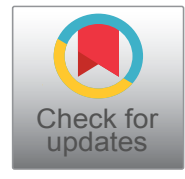

* Corresponding author: Ramakrishna Venkatesh, Division of Urologic Surgery, Washington University School of Medicine in St. Louis, MO, USA

\begin{abstract}
Introduction and objectives: Xanthogranulomatous pyelonephritis (XGP) has historically been managed with open nephrectomy. In the era of minimally invasive surgery, a small number of reports have evaluated the use of a laparoscopic approach in XGP, with variable results. We evaluated the complications of nephrectomy for XGP over the last 18 years. This represents one of the largest series to date comparing laparoscopic and open nephrectomy for XGP.

Methods: Retrospective review of all nephrectomy specimens from May 2001 to August 2018 disclosed 28 patients with pathologically confirmed XGP. 28 patients underwent nephrectomy (16 laparoscopic or robot-assisted laparoscopic, 12 open). 3 laparoscopic cases were converted to open procedures. The probability of undergoing laparoscopic nephrectomy significantly increased over time $(p=$ 0.063).

Results: There were no differences in overall complication rate $(43.8 \%$ vs. $58.3 \%, p=0.704)$, Clavien I and II complications ( $25 \%$ vs. $33.3 \%, p=0.691)$, Clavien III and IV complications $(18.8 \%$ vs. $25 \%, p=1.0)$, readmissions $(25 \%$ vs. $25 \%, p=1.0$ ), or mean operative time (189 min. vs 211 min., $p=0.276$ ) between the laparoscopic and open groups, respectively. Estimated blood loss ( $381 \mathrm{~mL}$ vs. 827 $\mathrm{mL}, \mathrm{p}=0.015)$ and intraoperative transfusion rate $(12.5 \%$ vs. $58.3 \%, p=0.017$ ) were significantly higher in the open group. There were no perioperative mortalities in either group. The mean hospital length of stay was 8 days for the open group and 3.2 in the laparoscopic group ( $<<0.001)$. Multivariate analysis showed patients with preoperative glomerular filtration rate of $<60$ or blood loss $>1$ liter were more likely to suffer a major complication or require readmission.
\end{abstract}

Conclusions: Although early reported experience with laparoscopic nephrectomy for XGP was not favorable, our larger and more contemporary series demonstrates it can be performed safely with less blood loss, shorter hospital stay and similar complication rates compared to the open approach. However, nephrectomy for XGP continues to be associated with high complication rate.

\section{Introduction}

Xanthogranulomatous pyelonephritis (XGP) is a severe and chronic renal inflammatory condition resulting in destruction of kidney parenchyma and replacement with pathognomonic lipid laden macrophages. It is often associated with obstructive nephrolithiasis and infection with Proteus mirabilis or E. coli organisms [1].

Open nephrectomy has traditionally been the management of choice for XGP given the local inflammation potentially precluding minimally invasive approaches. Multiple small series utilizing laparoscopy have been reported with mixed results [2-7]. Bercowsky, et al. described Washington University's early experience in 1999 reporting significantly higher complication rates and longer operative times, thus concluding that the laparoscopic approach is not justified [2]. We report here an updated and more robust contemporary series of our experience managing XGP.

\section{Patients and Methods}

After obtaining Institutional Review Board approval, we performed a retrospective review of all cases

Citation: Raval N, Benabdallah J, Leslie SL, Vetter J, Ramakrishna VR, et al. (2020) Complications of Laparoscopic Versus Open Nephrectomy for Xanthogranulomatous Pyelonephritis: A Contemporary Series. Int Arch Urol Complic 6:071. doi.org/10.23937/2469-5742/1510071

Accepted: April 13, 2020: Published: April 15, 2020

Copyright: (C) 2020 Raval N, et al. This is an open-access article distributed under the terms of the Creative Commons Attribution License, which permits unrestricted use, distribution, and reproduction in any medium, provided the original author and source are credited. 
Table 1: Patient characteristics.

\begin{tabular}{|c|c|c|c|}
\hline & Open Surgery & Laparoscopy & P Value \\
\hline & $(N=12)$ & $(N=16)$ & \\
\hline Mean Age (year) & 56.5 & 50 & 0.245 \\
\hline Sex $(\%)$ & & & 0.687 \\
\hline Male & 25 & 37.5 & \\
\hline \multirow[t]{2}{*}{ Female } & \multirow[t]{2}{*}{75} & & \\
\hline & & 62.5 & \\
\hline Mean BMI & 31.2 & 33.6 & 0.353 \\
\hline ASA $(\%)$ & & & 1 \\
\hline 1 or 2 & 55.6 & 56.3 & \\
\hline 3 & 44.4 & 43.8 & \\
\hline eGFR < 60 (\%) & 16.7 & 25 & 0.673 \\
\hline Mean Creatinine (mg/dL) & 1.34 & 1.12 & 0.501 \\
\hline Laterality & & & 0.441 \\
\hline Left & 50 & 68.8 & \\
\hline Right & 50 & 31.3 & \\
\hline Mean Function of XGP kidney (\%) & 4 & 5.7 & 1 \\
\hline Mean Hemoglobin (g/dL) & 10.8 & 11.9 & 0.185 \\
\hline History of Stones (\%) & 25 & 43.8 & 0.434 \\
\hline History of Sepsis (\%) & 25 & 12.5 & 0.624 \\
\hline Nephrostomy Placement (\%) & 33.3 & 43.8 & 0.705 \\
\hline
\end{tabular}

Table 2: Operative and postoperative data.

\begin{tabular}{|l|l|l|l|}
\hline & Open Surgery & Laparoscopy & P Value \\
\cline { 2 - 4 } & $\mathbf{( N = 1 2 )}$ & $\mathbf{( N = 1 6 )}$ & 0.276 \\
\hline Mean OR Time (min) & 211 & 189 & $0.015^{*}$ \\
\hline Mean EBL (mL) & 827 & 381 & 0.432 \\
\hline Psoas muscle involvement (\%) & 41.7 & 25 & 0.121 \\
\hline Other organ involvement (\%) & 58.3 & 25 & $0.017^{*}$ \\
\hline Intraoperative blood transfusion (\%) & 12.5 & 0.418 \\
\hline Post-operative blood transfusion (\%) & 58.3 & 18.8 & \\
\hline Post-op complications & 33.3 & & 0.704 \\
\hline Overall & & 43.8 & 0.691 \\
\hline Clavien I-II (\%) & 58.3 & 25 & 1 \\
\hline Clavien III-IV (\%) & 33.3 & 18.8 & $<0.001^{*}$ \\
\hline Mean LOS (days) & 25 & 3.2 & 1 \\
\hline Readmission (\%) & 8 & 25 & \\
\hline *significant & 25 & & \\
\hline
\end{tabular}

of nephrectomy at Washington University School of Medicine in St. Louis from May 2001 to August 2016. Demographics and data were collected, including operative approach, intraoperative and postoperative variables (Table 1 and Table 2). The rationale for choosing a laparoscopic versus open approach was surgeon-dependent accounting for their expertise or opinion on the safest method given the presentation.
In all, 28 patients with pathologic XGP treated with radical nephrectomy were included in our analysis. 16 patients underwent laparoscopic nephrectomy (including 1 robot-assisted laparoscopic) and 12 patients underwent open nephrectomy.

The mean age was 56.5 years in the open group and 50 years in the laparoscopic group $(p=0.245)$. The fe- 
male to male ratio was $3: 1$ in the open group and 1.67:1 in the laparoscopic group $(p=0.687)$. Both groups were also similar in their comorbidities, preoperative lab values and laterality of affected kidney. A summary of the preoperative demographics in each group can be seen in Table 1.

A presumed preoperative diagnosis of XGP was apparent in 10 of the laparoscopic patients $(62.5 \%)$ based on clinical evidence. Other preoperative diagnoses in the laparoscopic patients included renal malignancy ( $\mathrm{n}$ $=3)$, and non-functional kidney $(n=3)$. Flank pain and infection were the most common presenting symptoms in the laparoscopic group representing $57 \%$ of patients. Conversion to an open procedure occurred in 3 of the laparoscopic cases for either failure to progress due to inflammatory fibrosis $(n=2)$ or venous bleeding $(n=1)$. In the open group, the majority $(75 \%, n=9)$ had a suspected diagnosis of XGP. Flank pain and infection were only present in $20 \%$ of the open patients.

Laparoscopic nephrectomies were performed trans peritoneally using a standard 3 or 4-port technique (Figure 1). Hand assistance using a Gelport occurred in 4 patients. A Harmonic Scalpel (Ethicon Endo-surgery,
Cincinatti, $\mathrm{OH}$ ) or Sonicision (Covidien-Medtronic, Minneapolis, MN) was used in all laparoscopic cases for ultrasonic dissection and hemostasis. The open surgical approach was performed using a flank incision in all but one patient who was thought to have a bowel fistula necessitating a midline incision. Intact specimens were removed in all cases without morcellation. Dense adhesions and inflammation were encountered and noted by all surgeons. Of note, $56 \%$ of the laparoscopic nephrectomies were performed by a single experienced laparoscopic surgeon (RSF). The remainder were performed by a combination of 7 different surgeons with variable experience. Open surgeries were performed by 10 different physicians over this time period. The likelihood of a patient with XGP undergoing a laparoscopic surgery increased over time $(p=0.063)$ (Figure 2$)$.

The Wilcoxon sum-rank test was used to compare continuous variables and Fisher's exact test was used to compare categorical variables. We performed a multivariate analysis to look for predictors of major complications or readmissions. Complications were graded according to the Clavien-Dindo classification [9]. P-values less than 0.05 were considered statisti-
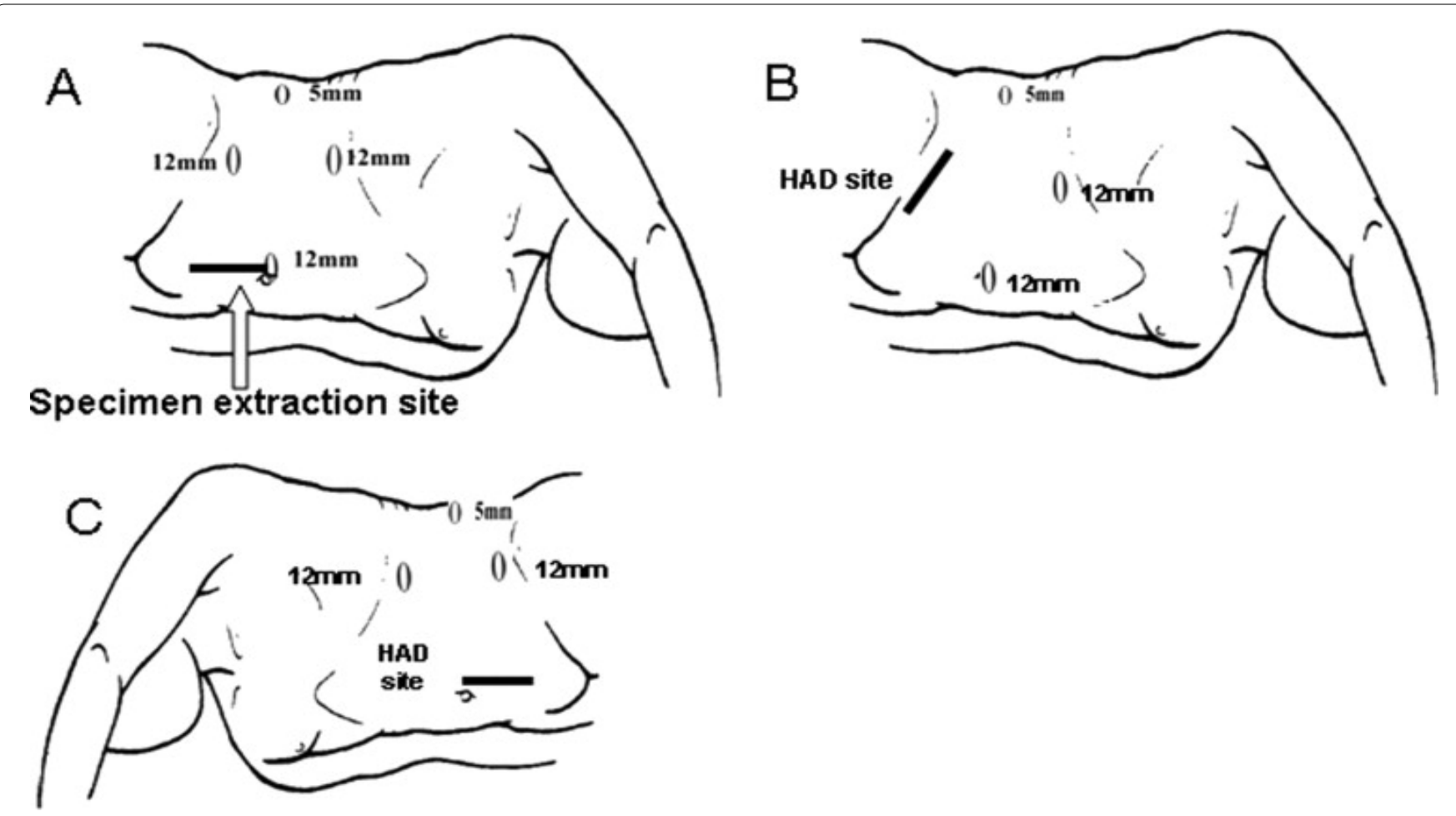

Figure 1: Standard port-placement for LN and HALN [8].

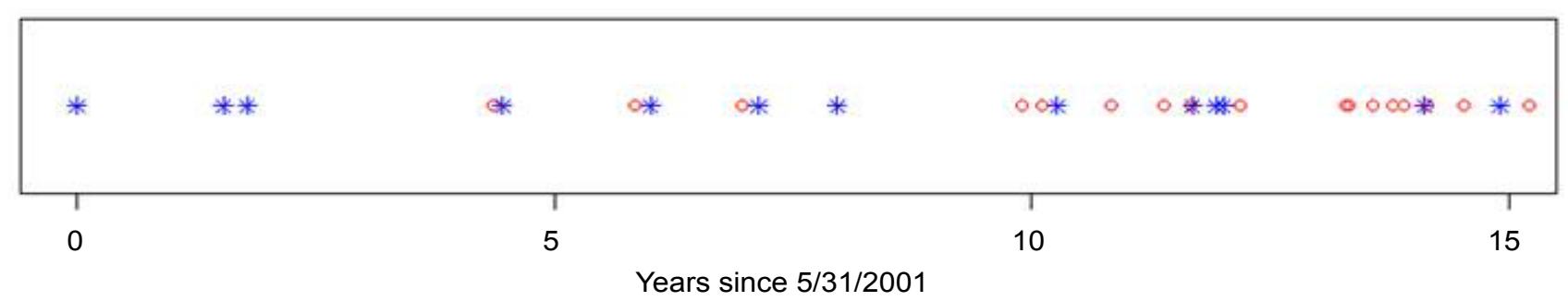

Figure 2: Management of XGP over Time (Star = Open; Circle = Laparoscopic). 
cally significant.

\section{Results}

Laparoscopic nephrectomy was successful in 16 patients $(85.7 \%)$ with conversion to open in 3 cases $(15.8 \%)$, due to failure to progress $(n=2)$ or venous bleeding $(n=1)$. There was no significant difference in mean operative time between open and laparoscopic approaches ( 211 vs. 189 minutes; $p=0.308$ ). Drains were placed intraoperatively in $100 \%$ of the open cases, but only $43.8 \%$ of the laparoscopic cases $(p<0.05)$. The mean estimated blood loss (EBL) was significantly more in the open group at $827 \mathrm{~mL}$ versus $381 \mathrm{~mL}$ in the laparoscopic group $(p=0.015)$. The patient who was converted from laparoscopic to open for venous bleeding suffered the greatest blood loss with 4 liters. Along with this discrepancy in blood loss, the need for intraoperative blood transfusion was likewise significantly higher in the open group than the laparoscopic group (58.3\% vs. $12.5 \% ; p=0.017$ ).

Overall the likelihood of complications was not significantly different between groups with rates of $58.3 \%$ in the open patients and $43.8 \%$ in the laparoscopic patients $(p=0.704)$. When stratified by Clavien grade, the groups remained similar (Table 2 ). Three patients in the open group suffered pleurotomies that were repaired, none requiring long term chest tubes. One bowel injury was seen in the open group which was also recognized and repaired intraoperatively. On the laparoscopic side, the aforementioned patient that was converted to open for venous bleeding also suffered a small splenic laceration and diaphragmatic injury.

The only other significant intraoperative complication was in a patient who had a prior partial nephrectomy and was referred to our center after the pathology was revealed to be XGP. The decision was made to pursue a laparoscopic completion nephrectomy, which found extreme fibrosis in the hilar plains. The inferior vena cava was mistaken for the renal vein and subsequently stapled and cut. Fortunately, the patient had excellent collateral venous return and did not require heroic vascular surgery. Blood loss was minimal, but the patient's blood pressure was labile in the recovery room necessitating a return to the operating room for an exploratory laparoscopy. No bleeding was found and the remainder of the patient's postoperative course was unremarkable. Our analysis of several pre- and postoperative variables found that patients with preoperative glomerular filtration rate of $<60 \mathrm{ml} / \mathrm{min} / 1.73 \mathrm{~m}^{2}(\mathrm{p}=$ $0.027)$, blood loss $>1$ liter $(p=0.037)$, or hospital stay

Table 3: Postoperative complications and readmissions.

\begin{tabular}{|c|c|c|c|c|}
\hline & $\begin{array}{l}\text { Clavien } \\
\text { Score }\end{array}$ & $\begin{array}{l}\text { Open (O) or } \\
\text { Laparoscopic (L)? }\end{array}$ & $\begin{array}{l}\text { Readmitted } \\
(\mathrm{Y} / \mathrm{N}) ?\end{array}$ & Readmission Diagnosis \\
\hline \multicolumn{5}{|l|}{$\begin{array}{l}\text { Postoperative Complications (14 } \\
\text { patients) }\end{array}$} \\
\hline Numbness in lower extremities & 1 & $\mathrm{~L}$ & $\mathrm{~N}$ & NA \\
\hline $\begin{array}{l}\text { Retroperitoneal hematoma, } \\
\text { nausea and sensitivity to smells }\end{array}$ & 2 & $\mathrm{~L}$ & $\mathrm{~N}$ & NA \\
\hline Arrhythmia & 2 & $\mathrm{~L}$ & $\mathrm{Y}$ & Ileus \\
\hline Postoperative blood transfusion & 2 & $\mathrm{~L}$ & $\mathrm{~N}$ & NA \\
\hline Postoperative blood transfusion & 2 & $\mathrm{O}$ & $\mathrm{N}$ & NA \\
\hline $\begin{array}{l}\text { Metabolic acidosis secondary to } \\
\text { Acute Kidney Injury }\end{array}$ & 2 & $\mathrm{O}$ & $\mathrm{N}$ & NA \\
\hline $\begin{array}{l}\text { Nausea, vomiting and dehydration; } \\
\text { psoas abscess }\end{array}$ & 2 & O & $\mathrm{Y}$ & $\begin{array}{l}\text { Nausea, vomiting and dehydration; } \\
\text { psoas abscess }\end{array}$ \\
\hline Labile blood pressure & 2 & $\mathrm{O}$ & $\mathrm{Y}$ & $\begin{array}{l}\text { Accidental fall secondary to stage } 3 \\
\text { chronic kidney disease, dizziness, } \\
\text { hypokalemia and lactic acidosis }\end{array}$ \\
\hline $\begin{array}{l}\text { Abdominal abscess requiring } \\
\text { percutaneous drainage }\end{array}$ & $3 a$ & $\mathrm{~L}$ & Y & Abdominal fluid collection/abscess \\
\hline $\begin{array}{l}\text { Retroperitoneal abscess with } \\
\text { cutaneous fistula }\end{array}$ & $3 a$ & O & $\mathrm{Y}$ & $\begin{array}{l}\text { Retroperitoneal abscess with } \\
\text { cutaneous fistula }\end{array}$ \\
\hline $\begin{array}{l}\text { Nausea, vomiting and fluid } \\
\text { collection in renal bed }\end{array}$ & $3 b$ & $\mathrm{~L}$ & $\mathrm{Y}$ & Fluid collection in renal bed \\
\hline $\begin{array}{l}\text { Labile blood pressure and pulse, } \\
\text { acute renal failure }\end{array}$ & 4 & $\mathrm{~L}$ & $\mathrm{Y}$ & Wound infection \\
\hline Wound dehiscence & 4 & O & $\mathrm{N}$ & NA \\
\hline $\begin{array}{l}\text { Acute Respiratory Distress } \\
\text { Syndrome }\end{array}$ & $4 b$ & 0 & $\mathrm{~N}$ & NA \\
\hline
\end{tabular}


$>9$ days $(p=0.034)$ were more likely to suffer a major complication or require readmission.

Post-operatively the need for blood transfusions was similar $(p=0.418)$. The mean length of stay in the laparoscopic group was 3.2 days and 8 days in the open surgical group $(p<0.001)$. There were no deaths in either group. A summary of operative and postoperative data can be found in Table 2. There were significant complications in both groups. Table 3, details the postoperative complications and readmission diagnoses for the fourteen patients who suffered a complication. There were seven patients with a complication in each group. Complications ranged from mild (numbness in extremities) to severe (acute renal failure). Out of the fourteen patients who suffered a complication, seven were readmitted. No readmissions occurred in the absence of a postoperative complication.

\section{Discussion}

Although not commonly seen, XGP remains a challenge for the urologic surgeon. The chronic inflammation leads to significant perinephric fibrosis and adhesion to adjacent organs. Computed tomography (CT) remains the gold-standard preoperative imaging although the ability to predict fibrosis remains in question $[10,11]$. In our series, only 19 of the 28 patients had a preoperative diagnosis of XGP based on CT imaging and clinical findings. The "classic" clinical presentation of XGP involves a renal mass, non-functioning kidney, renal calculi, and infection [1]. Despite this being the classic presentation, it is rarely seen, thus making XGP one of the many "great imitators" in medicine [12]. In fact, none of our patients had all 4 of the aforementioned findings.

Nephrectomy has long been established as the management of choice for XGP, except in rare cases of a focal variant. Since the initial report of laparoscopic nephrectomy by Clayman, et al. in 1991, a minimally invasive approach to kidney surgery has been widely adopted when possible [13]. The shift from open surgery is due to the demonstrable benefit in morbidity, pain and cosmesis. This is especially true in cases of malignant kidney disease, non-functional kidney, renovascular disease and even donor nephrectomy $[13,14]$. However, XGP had been considered a contraindication to a laparoscopic approach, owing to the known difficulty in dissection.

Bercowsky, et al. described 9 patients with XGP, of whom 5 underwent laparoscopic nephrectomy [2]. With a $60 \%$ complication rate, one conversion to open, significantly longer operative time and a similar postoperative course, the group concluded "the benefits of laparoscopic nephrectomy, at present, do not extend to patients with XGP". This cautionary tale was likely heeded at most centers as only a handful of small case series have emerged since then describing the use of laparos- copy with XGP [3-7]. Most of the reports have demonstrated the feasibility of laparoscopic nephrectomy in XGP, with some showing minimally improved outcomes compared with open $[3,4]$. All reports however, have added the caveat that the experience of the surgeon is key. Our series, which is one of the largest reported laparoscopic XGP series to date, mirrors this sentiment. Even with significant experience, postoperative complications and readmissions are common, highlighting the difficulty of this procedure.

In many retrospective XGP series, including ours, there may be some selection bias as most surgeons who choose a laparoscopic approach in these patients are likely experienced and comfortable with the challenge. In our series, the most experienced laparoscopist in the group performed almost half of the cases. Randomized controlled trials would be needed to truly demonstrate a benefit of a laparoscopic approach, however, this may prove challenging given the rarity of XGP [6].

In our institution's updated experience with XGP, we have demonstrated that the majority of cases can be completed safely laparoscopically. Open conversion, if necessary, does not portend a poor outcome. Our $15.8 \%$ conversion rate is similar to previously reported series and typically occurs due to failure to progress rather than a catastrophic complication. Those patients who were successfully treated laparoscopically do seem to benefit from less blood loss, a lower transfusion rate, and a significantly shorter hospital stay with no increase in complications or readmission rate. We emphasize, however, that if there is concern for patient safety or lack of progression with a prolonged operative time, surgeons should not hesitate to convert to an open procedure. Open conversion can be necessary in some cases to safely manage a major intraoperative complication.

We recognize the limits of this study including the retrospective nature, the variability of surgeon experience, and the size of the series. We do believe this adds to the growing body of literature in support of cautious use of laparoscopy in XGP patients, fortunately a rare disease.

\section{Conclusions}

Laparoscopic renal surgery has evolved over the last 25 years with continuously expanding indications. Although the benefits to laparoscopic management of XGP may not be as compelling as other conditions, they are demonstrable and significant. A minimally invasive approach to nephrectomy should be considered in these patients. Our series spans a single institution's 15-year experience demonstrating a high rate of successful laparoscopic surgery in XGP patients. The results suggest less morbidity and shorter convalescence when compared to open surgery with no difference in complica- 
tion rate. Our ability to safely treat XGP in a minimally invasive fashion will certainly progress as our diagnostic and surgical tools continue to improve.

\section{References}

1. Eastham J, Ahlering T, Skinner E (1994) Xanthogranulomatous pyelonephritis: Clinical findings and surgical considerations. Urology 43: 295-299.

2. Bercowsky E, Shalhav AL, Portis A, Elbahnasy AM, McDougall EM, et al. (1999) Is the laparoscopic approach justified in patients with xanthogranulomatous pyelonephritis? Urology 54: 437-443.

3. Khaira SH, Shah DB, Wolf JS (2005) Laparoscopic and open surgical nephrectomy for xanthogranulomatous pyelonephritis. J Endourol 19: 813-817.

4. Kapoor R, Vijjan V, Singh K, Goyal R, Mandhani A, et al. (2006) Is laparoscopic nephrectomy the preferred approach in xanthogranulomatous pyelonephritis? Urology 68: 952-955.

5. Vanderbrink BA, Ost MC, Rastinhead A, Anderson A, Badlani $\mathrm{GH}$, et al. (2007) Laparoscopic versus open radical nephrectomy for xanthogranulomatous pyelonephritis: Contemporary outcomes analysis. J Endourol 21: 65-70.

6. Rosoff JS, Raman JD, Del Pizzo JJ (2006) Feasibility of laparoscopic approach in management of xanthogranulomatous pyelonephritis. Urology 68: 711-714.
7. Qadan M, Wines M, Tolley DA (2009) Xanthogranulomatous pyelonephritis: No longer a contraindication for laparoscopic surgery? BJMSU 2: 34-38.

8. Venkatesh R, Belani JS, Chen C, Sundaram CP, Bhayani SB, et al. (2007) Prospective randomized comparison of laparoscopic and hand-assisted laparoscopic radical nephrectomy. Urology 70: 873-877.

9. Dindo D, Demartines N, Clavien PA (2004) Classification of surgical complications. Ann Surg 240: 205-213.

10. Subramanyan BR, Megibow AJ, Raghavendra BN, Bosniak MA (1982) Diffuse xanthogranulomatous pyelonephritis: Analysis by computed tomography and sonography. Urol Radiol 4: 5-9.

11. Zorzos I, Moutzouris V, Korakiantis G (2003) Analysis of 39 cases of xanthogranulomatous pyelonephritis with emphasis on CT findings. Scand J Urol Nephrol 37: 342-347.

12. Zorzos I, Moutzouris V, Petraki C, Katsou G (2002) Xanthogranulomatous pyelonephritis - the "great imitator" justifies its name. Scan J Urol Nephrol 36: 74-76.

13. Clayman RV, Kavoussi LR, Soper NJ, Dierks SM, Meretyk S, et al. (1991) Laparoscopic nephrectomy: Initial case report. J Urol 146: 278-282.

14. Rassweiler J, Tsivian A, Kumar AV, Lymberakis C, Schulze $M$, et al. (2003) Oncological safety of laparoscopic surgery for urological malignancy: Experience with more than 1,000 operations. J Urol 169: 2072-2075. 